\title{
Plan inicial, progresos explícitos y evaluación de una trama de feedforwarding sobre campus virtual en una asignatura de matemáticas
}

Fabregat, J. ${ }^{\text {, }}$, Pelayo, I. $^{\text {b }}$,

${ }^{a}$ Departament de Matemàtiques, Escola Superior d'Agricultura de Barcelona (UPC), jaime.fabregat@upc.edu, 'bepartament de Matemàtiques, Escola Superior d'Agricultura de Barcelona (UPC), ignacio.m.pelayo@upc.edu

\begin{abstract}
This paper presents the work carried out during the last academic years by a team of teachers from the Universitat Politècnica de Catalunya-Barcelona Tech (UPC), with the aim of clarifying a set of advantages of a formative and individualized feed-forward evaluation causing reflection - action, forging compromise between student and professors, being not restricted to the truefalse items, offering a quick feedback and guiding.

The effort has been focused on Mathematics, during the first semester of the degree in agricultural engineering. This initiative offers a number of exams to the students, in the form of questionnaires, first with and then without feedback, to enliven learning. Students have first considered a test with repeated feedback in order to respond properly to a set of questions and then they have been faced a similar test without feedback.

It has been used a support from ICT, in order to observe various profits, focusing on its contribution in terms of improvement in the assessment, the level of the use of the resource by the students, their loyalty and achieving benefits.

About two hundred students have participated every academic year, with pairs of exams supported by WIRIS, using Moodle.
\end{abstract}

Keywords: assessment, feedforwarding, innovation, mathematics, feedback

\footnotetext{
Resumen

La comunicación recoge el trabajo, por segundo año, de profesores de la Universitat Politècnica de Catalunya (UPC) para aclarar ventajas de una evaluación formativa "feedforwarding", que cause reflexión-acción, que esté adecuadamente personalizada, que forje compromiso entre las poblaciones estudiantil y docente, que no se circunscriba a un "correcto-incorrecto", que realimente con rapidez y que tutele.

El afán ha incidido, y reincidido, sobre "Matemáticas" del primer cuatrimestre de grados en ingeniería. Han sido propuestos a los alumnos unos exámenes, en forma de cuestionarios, con y sin realimentación, para avivar el aprendizaje. Los estudiantes han considerado primero un examen
}

(cc)) EY-NC-ND 2016, Universitat Politècnica de València 
Plan inicial, progresos explícitos y evaluación de una trama de feedforwarding sobre campus virtual en una asignatura de matemáticas

con realimentación repetida hasta responder apropiadamente unas cuestiones para, después, enfrentarse a otro análogo sin realimentación.

Ha sido utilizado un sostén de tecnologías de la información y la comunicación, accediendo a examinar provechos de la labor, centrándose sobre todo en su aporte en términos de mejora en la evaluación, de empleo del recurso por los alumnos, de su fidelización y de logro de beneficios.

Cada año ha habido una actuación sobre unos dos centenares de estudiantes, con pares de exámenes formados con apoyo de WIRIS (cada par ligado a un contenido temático), usándose Moodle.

Palabras clave: evaluación, feedforwarding, innovación, matemáticas, realimentación

\section{Introducción}

El alumno universitario no siempre abre los ojos, ni siquiera mínimamente, de modo explícito y por sí mismo, para descubrir - visualizándolo y cavilando - que la cara formativa de la evaluación importa mucho. Debería pasar que el estudiante no cediese en que, de suyo, fuera otra cara que la formativa aquella que más se trazase, se fraguase, se pusiese en marcha, se asentase y valiese en educación superior, aun ocurriendo que las caras sumativa y certificativa sean las que más se le revelen. Se ha alertado, hace tiempo ya, sobre paradojas que se producen en el campo de la evaluación (Santos Guerra, 1999), por ejemplo, sobre cómo se promociona, desde el sistema universitario y el no universitario, que el estudiante entre en el juego perverso de aprobar en vez de aprender, haciendo (muchas veces sin querer) que lo primero sea distinto y más fácil que lo segundo.

En la cara formativa de la evaluación, el "feedback", la realimentación, tiene cabida y libra un papel muy notable. Resulta factible, en particular, una ponderación del "feedforwarding", como partícipe en el rol de una evaluación formativa realimentadora.

Producir, llevar a cabo y valorar proyectos educacionales con metodologías que trasciendan las propuestas más tradicionales, y respondan a las necesidades que se activan en los aprendices de nuestro tiempo, constituye un claro desafío (Castañeda, 2014).

\section{Objetivos}

Que el aprendizaje significativo de las ciencias, por parte de los estudiantes, es un trabajo con un índice de fracaso elevado, representa una afirmación fundamentada que difícilmente puede sorprender a los profesores de ciencias (Campanario y Otero, 2000) ni, en particular, a los profesores de matemáticas. Ni causa de sorpresa debería tampoco ser que se diga que la evaluación es un tema clave, pero que asimismo es una asignatura pendiente (Bartolomé, 2012).

(c)) EY-NC-ND 2016, Universitat Politècnica de València 
El asunto expuesto aquí, un caso de evaluación formativa, teóricamente "feedforwarding", tiene como objetivo fundamental el impacto de favorecer el aprendizaje de los estudiantes en el área de matemáticas, en correspondencia con los deseos institucionales. Se ponen a su servicio, acciones en las que los propios estudiantes trabajen como actores. Los docentes implicados se alinean con la consideración general acerca del importante papel que tiene la evaluación a la hora de fijar los contenidos y los niveles que serán objeto de atención por parte del estudiante (Benito y Cruz, 2005) y con la convicción de que sus alumnos aprenden de una manera determinada en función de la forma en que se evalúa (Gargallo et al., 2015).

Un objetivo complementario movilizador finalista ha sido que evaluaciones conducentes a unas notas de valor sumativo se transformen en evaluaciones que sean claramente formativas a los ojos de los estudiantes. Otro objetivo adicional ha consistido en conseguir que tales acciones evaluadoras tengan un papel predictor de los resultados de aprendizaje final, tanto para estudiantes como para profesores.

\section{Desarrollo de la innovación}

Se ha tratado de que el equipo docente unido aplique esfuerzos a favor de unos medios con los que cada estudiante no se plante ante unos pequeños desafíos (diseñados en forma de cuestionarios) sino que, tras experimentarlos, los afronte para que vaya sobresaliendo de ellos, promoviendo un cambio acumulativo en él. Se ha tratado de asistir a cada alumno repetidamente, con un carácter particularizado, para que advierta no sólo sus errores sino asimismo cuáles son orígenes posibles de los mismos y para que anote vías para emerger desde ellos. Se ha tratado de forjarlo todo de modo que se sorteen tiempos muertos en la preparación del estudiante y de forma tal que los profesores puedan lograr tener en cuenta a muchos estudiantes de variados niveles. Se ha tratado de hacer las cosas con un estilo que las estructuras no estorben. Y se ha tratado de que la innovación constituya un aporte a armar cada mente en un vivo combate para la lucidez (Morin, 2000).

El despliegue original para los objetivos expuestos se ha desarrollado sobre unos dos centenares de estudiantes de matemáticas de primer cuatrimestre en la Escola Superior d'Agricultura de Barcelona, en titulaciones de ingeniería de biosistemas, durante los cursos 2014-15 y 2015-16, con un desarrollo incremental. Dos modalidades (una adaptativa y una estándar) de unos exámenes, con interrogantes sobre la disciplina, se han dispuesto para que sean asequibles fácilmente desde el ordenador y se responda a ellos, causándose que se proyecte así una energía suplementaria destinada a la enseñanza y al aprendizaje. La responsabilidad de profesores y estudiantes ha dado su "sí" a este nuevo orden, que proporciona asimismo autoevaluación.

Cinco exámenes dobles se colocaron el primer año en el campus virtual (Universitat Politècnica de Catalunya Barcelona Tech, 2016) y seis exámenes dobles se han dispuesto el segundo año, en ambos casos con cuestiones sobre la materia enseñada, no iguales ni entre estudiantes ni para un mismo estudiante (si bien análogas), contándose para su concepción con las potencialidades debidas a WIRIS (Wiris, 2016). Se ha usado Moodle (Instituto Nacional de Tecnologías Educativas y de Formación del Profesorado, 2016), versión 2.6.2.

(c) EY-NC-ND 2016, Universitat Politècnica de València

Congreso In-Red (2016) 
Plan inicial, progresos explícitos y evaluación de una trama de feedforwarding sobre campus virtual en una asignatura de matemáticas

Se ha dispuesto que cada estudiante se enfrente a las evaluaciones en solitario, fundamentándose en consideraciones teóricas, contextuales y pragmáticas. Se ha calculado dificultar el incumplimiento de lo marcado, aunque no se pretenda refrendar que ello se haya conseguido.

Cada par de exámenes se emparentó el primer año con una de cinco diferentes unidades temáticas (las cinco primeras del curso) y, progresando, un par de exámenes se ha entroncado durante el segundo año ya con cada una de las seis unidades de las que consta la materia. Los exámenes se distribuyeron el primer año al ultimarse el desarrollo de cada unidad; el segundo año se han distribuido de forma consecutiva en las últimas semanas del cuatrimestre. Se elaboró un banco de preguntas por cuestionario que incorporaba entre $18 \mathrm{y}$ 24 preguntas el primer año, mientras que el banco ya incorporaba entre 24 y 30 preguntas el segundo año. Más detalles aparecen en la tabla 1.

Tabla 1: Unidades inmersas en exámenes para cada curso y número de preguntas formuladas

\begin{tabular}{|l|l|c|c|}
\hline & & $14-15$ & $15-16$ \\
\hline Álgebra lineal & $\mathrm{C} 1$ & 12 & 12 \\
\hline Geometría & $\mathrm{C} 2$ & 12 & 12 \\
\hline Introducción al cálculo en una variable & $\mathrm{C} 3$ & 10 & 12 \\
\hline Cálculo diferencial en una variable & $\mathrm{C} 4$ & 10 & 12 \\
\hline Funciones de varias variables & $\mathrm{C} 5$ & 10 & 12 \\
\hline Optimización & $\mathrm{C} 6$ & -- & 12 \\
\hline
\end{tabular}

Se ha encargado a cada estudiante de matemáticas en ingeniería de biosistemas que siga los exámenes mediante enlace por red al campus virtual, en donde él se encuentre y cuando lo desee (dentro de una franja temporal de 48 horas). Cabe que el estudiante vaya apelando a todo tipo de auxilios mientras pretende responder a los interrogantes, pero procediendo invariablemente a título propio: no se puso ninguna cortapisa a todo ello el primer año, pero se ha aconsejado a los estudiantes el segundo año que procuren no usar más herramientas que las permitidas en los exámenes convencionales.

Se decidió, para esta iniciativa, que se ofreciera un par de exámenes del tipo cuestionario de respuesta múltiple, con cuatro apartados a título de opciones, en cada una de las ocasiones, debiendo el estudiante afanarse en primer lugar ante el reto de una versión que multirealimenta siempre que se comete error.

El estudiante contextualiza en esta versión primera, como ya se acaba de indicar en síntesis, unas realimentaciones anotadas tras sus contestaciones erróneas. Tales realimentaciones tratan de exponer la inadecuación "per se" de las respuestas erradas (por su "sinsentido", incompatibilidad, discordancia, valor desorbitado, carácter incompleto,...) y/o tratan de descubrir una vía que arroje luz para hallar la contestación correcta (definición de alguno de los conceptos implicados, causas de posible confusión,...). 
En las realimentaciones a veces se expone un contraejemplo oportuno, a veces se aprovecha una respuesta incorrecta con respecto al enunciado para referir otro enunciado del que sí sería una respuesta correcta, a veces se dan argumentos sobre una condición necesaria que no se cumple,... Las realimentaciones glosan aspectos significativos, hacen referencia a objetivos de aprendizaje derivados de la labor, aluden a asuntos no singulares sino trasladables, apuntan tanto a aspectos positivos como negativos en torno a los conocimientos comprobados y orientan procesos autoreguladores.

Cabe expresar, en cuanto a envolturas formales, que las frases esgrimidas para las realimentaciones son amigables o neutras siempre, nunca agresoras ni ásperas. Se ha buscado la finura gramatical y el orden en la forma, por medio de una buena redacción en términos de ortografía, claridad y estructura coherente, y de un modo calculado para insinuar cambios a partir de las equivocaciones propias. Las realimentaciones son de expresión abierta y, partiendo de la revocación implícita de la respuesta equivocada, no aportan las contestaciones correctas sino que guían al estudiante para que sea quien las logre.

Procede decir que las diferentes realimentaciones, en cuanto al compromiso en vertientes emocionales, sortean disminuir la autoestima (animan, antes al contrario, a sacar un partido pertinente de uno mismo), median con acentos de asertividad (utilizando el condicional y/o entradas más blandas que duras) y son motivadoras (alientan).

Posteriormente a haber trabajado, como base, con la versión primera del cuestionario se despliega ante el estudiante una versión convencional de cuestionario, semejante a la inicial (del mismo "prototipo") aunque sin realimentación, pero jamás antes de haber obtenido precedentemente la contestación correcta a todos los interrogantes de la versión inicial. Se concurre sólo a la versión postrema para extraer los datos que se incorporaran a la nota; la penalización por respuesta incorrecta no ha sido aplicada en ninguno de los años. Un volumen extenso de datos se consigue de la versión primera también, pero para revelar únicamente la contribución de esta forma de proceder. El lapso de tiempo máximo para responder cada cuestionario convencional se ha situado alrededor de las dos horas.

Los estudiantes se han podido enterar del proceso precedente antes de poner la innovación "en punto de partida", y ello en lo que respecta a su descripción, a los objetivos buscados, al perfil del procedimiento y al modo de obtener beneficios.

\section{Resultados}

El número de matriculados en la asignatura resultó ser de 243 durante el primer año de despliegue de la reforma (Fabregat et al., 2015), contando alumnos nuevos en la asignatura y alumnos que la habían cursado ya con anterioridad. La tabla 2 recoge el número total de estudiantes que respondió cada uno de los diez cuestionarios (cinco cuestionarios dobles: realimentado o adaptativo (CA) y convencional o simple (CS)); un total de 30 estudiantes no respondió ninguno.

En la tabla 2, de la misma manera, se ve la nota media obtenida en cada uno de los cuestionarios (sobre 10) (considerando el total de alumnos y considerando sólo los presentados) y, finalmente, se apunta el porcentaje de los que han respondido, ora sobre los que han contestado por lo menos en una ocasión, ora sobre el total.

(cc) EY-NC-ND 2016, Universitat Politècnica de València

Congreso In-Red (2016) 
Plan inicial, progresos explícitos y evaluación de una trama de feedforwarding sobre campus virtual en una asignatura de matemáticas

Tabla 2: Grado de participación y notas obtenidas el primer año, cuestionario a cuestionario

\begin{tabular}{|c|c|c|c|c|c|c|c|c|c|c|}
\hline $\begin{array}{l}\text { Total } \\
\text { de presentados } \\
14-15\end{array}$ & 180 & 162 & 192 & 182 & 191 & 184 & 157 & 147 & 160 & 148 \\
\hline $\begin{array}{l}\text { Nota media } \\
\text { sobre total }\end{array}$ & 5,19 & 5,24 & 5,98 & 6,89 & 6,48 & 7,08 & 4,94 & 5,83 & 4,72 & 4,60 \\
\hline $\begin{array}{l}\text { Nota media } \\
\text { sobre } \\
\text { presentados }\end{array}$ & 7,01 & 7,86 & 7,57 & 9,19 & 8,24 & 9,35 & 7,65 & 9,64 & 7,17 & 7,55 \\
\hline $\begin{array}{l}\text { \% sobre } \\
\text { presentados } \\
\text { alguna vez }\end{array}$ & 85 & 76 & 90 & 85 & 90 & 86 & 74 & 69 & 75 & 69 \\
\hline$\%$ sobre total & 74 & 67 & 79 & 75 & 79 & 76 & 65 & 60 & 66 & 61 \\
\hline
\end{tabular}

La tabla 3 acopia información del mismo género que la tabla 2 pero considerando el desarrollo de los cuestionarios en su conjunto.

Tabla 3: Grado de participación y notas obtenidas el primer año de los cuestionarios, considerados en conjunto

\begin{tabular}{|c|c|c|}
\hline $\begin{array}{l}\text { Total } \\
\text { de presentados } \\
14-15\end{array}$ & 176 & 165 \\
\hline $\begin{array}{l}\text { Nota media } \\
\text { sobre total }\end{array}$ & 5,46 & 5,93 \\
\hline $\begin{array}{l}\text { Nota media } \\
\text { sobre } \\
\text { presentados }\end{array}$ & 7,54 & 8,75 \\
\hline $\begin{array}{l}\text { \% sobre } \\
\text { presentado } \\
\text { alguna vez }\end{array}$ & 83 & 77 \\
\hline$\%$ sobre total & 72 & 68 \\
\hline
\end{tabular}

Una investigación al respecto sobre el primer año confirma, a la luz de las tablas anteriores, que los estudiantes respondieron los cuestionarios dobles (a pesar de no ser imprescindible por "obligatoriedad": el peso completo referido en la calificación era únicamente del 5\%, un $1 \%$ por cuestionario); intervinieron con una participación que ha superado el $60 \%$ persistentemente y rozando el $80 \%$ en la generalidad de los casos.

Cierto grado de acciones de abandono se puede apreciar cuando se pasa del cuestionario formativo al convencional. La tabla 4 evalúa el grado de relación lineal entre los pares de notas de los cuestionarios dobles. La calificación media de los cuestionarios convencionales realizados tras los formativos (estos últimos son los provistos de realimentaciones) supera, en todos los casos salvo uno, la calificación media de los formativos: se trata de un resultado educativo que era buscado, un resultado que era esperado y, muy frecuentemente, un resultado alcanzado.

(c) EY-NC-ND 2016, Universitat Politècnica de València 
Tabla 4: Coeficientes de correlación en el primer año entre notas de los cuestionarios dobles

\begin{tabular}{|c|c|c|c|c|c|}
\hline $\begin{array}{c}\text { Cuestionario A/S: } \\
\mathbf{1 4 - 1 5}\end{array}$ & CA1/CS1 & CA2/CS2 & CA3/CS3 & CA4/CS4 & CA5/CS5 \\
\hline Tema & $\begin{array}{c}\text { Álgebra } \\
\text { Lineal }\end{array}$ & Geometría & $\begin{array}{c}\text { Introducción } \\
\text { al Cálculo }\end{array}$ & $\begin{array}{c}\text { Cálculo } \\
\text { Diferencial }\end{array}$ & $\begin{array}{c}\text { Funciones } \\
\text { Varias Var. }\end{array}$ \\
\hline Correlación & 0,86 & 0,86 & 0,91 & 0,93 & 0 '90 \\
\hline
\end{tabular}

Las calificaciones conseguidas han sido altas en el cuestionario aportador de nota: su perfil mayoritario se ha ubicado entre el notable y el excelente. Los resultados antedichos no han tenido, sin embargo, su "consecuencia conveniente" en un perfeccionamiento de las calificaciones finales, según puede observarse en la tabla 5.

Yendo a la matriz 1 de la tabla 5, una mera inspección de lo que concierne a los totales en horizontal (correspondientes a los cuestionarios) y a los totales en vertical (correspondientes a las notas finales) muestra una disparidad clara de las distribuciones: puede distinguirse, por ejemplo, que la clase moda es "notable-excelente" para los cuestionarios mientras que la clase moda es "[5,7)"para las calificaciones finales. Los bajos valores presentes en numerosas celdas dificulta la aplicación directa de pruebas estadísticas de chi-quadrado.

El encuentro con las matrices 2 y 3 de la tabla 5 facilita consideraciones nuevas, observándose, verbigracia, que mientras más del $50 \%$ de las notas medias de los cuestionarios ocupan la franja "notable-excelente" ni el 5\% de las notas finales llega a ocupar esta franja, o que un $70 \%$ aprueba los cuestionarios pero no llega a su mitad (35\%) quienes aprueban según la nota final.

Tabla 5: Situación el primer año de notas finales (en vertical) respecto a distribución de notas de cuestionarios (en horizontal)

\begin{tabular}{|c|c|c|c|c|c|c|c|}
\hline $\begin{array}{l}\text { FINAL/CS: } \\
14-15\end{array}$ & NP & {$[0,3)$} & {$[3,4)$} & {$[4,5)$} & {$[5,7)$} & {$[7,10]$} & TOTAL \\
\hline NP & 15 & 3 & 2 & 2 & 4 & 4 & $\mathbf{3 0}$ \\
\hline$[0,3)$ & 6 & 9 & 9 & 0 & 10 & 20 & $\mathbf{5 4}$ \\
\hline$[3,4)$ & 2 & 2 & 1 & 3 & 6 & 18 & $\mathbf{3 2}$ \\
\hline$[4,5)$ & 4 & 1 & 3 & 2 & 11 & 24 & $\mathbf{4 5}$ \\
\hline$[5,7)$ & 0 & 2 & 1 & 4 & 8 & 56 & $\mathbf{7 1}$ \\
\hline$[7,10]$ & 0 & 0 & 0 & 0 & 1 & 10 & $\mathbf{1 1}$ \\
\hline TOTAL & $\mathbf{2 7}$ & $\mathbf{1 7}$ & $\mathbf{1 6}$ & $\mathbf{1 1}$ & $\mathbf{4 0}$ & $\mathbf{1 3 2}$ & $\mathbf{2 4 3}$ \\
\hline
\end{tabular}

Tabla 5 Matriz 1

\section{(c) EY-NC-ND 2016, Universitat Politècnica de València}




\begin{tabular}{|c|c|c|c|c|c|c|c|}
\hline $\begin{array}{c}\text { NOTA/CS: } \\
14-15\end{array}$ & NP & {$[0,3)$} & {$[3,4)$} & {$[4,5)$} & {$[5,7)$} & {$[7,10]$} & TOTAL \\
\hline NP & 50 & 10 & 6,67 & 6,67 & 13,33 & 13,33 & $\mathbf{3 0}$ \\
\hline$[0,3)$ & 11,11 & 16,66 & 16,66 & 0 & 18,52 & 37,04 & $\mathbf{5 4}$ \\
\hline$[3,4)$ & 6,25 & 6,25 & 3,13 & 9,38 & 18,75 & 56,25 & $\mathbf{3 2}$ \\
\hline$[4,5)$ & 8,89 & 2,22 & 6,67 & 4,44 & 24,44 & 53,33 & $\mathbf{4 5}$ \\
\hline$[5,7)$ & 0 & 2,82 & 1,41 & 5,63 & 11,27 & 78,87 & $\mathbf{7 1}$ \\
\hline$[7,10]$ & 0 & 0 & 0 & 0 & 9,09 & 90,9 & $\mathbf{1 1}$ \\
\hline TOtAL (\%) & 11,11 & 7,00 & 6,58 & 4,53 & 16,46 & 54,32 & $\mathbf{2 4 3}$ \\
\hline
\end{tabular}

Tabla 5 Matriz 2

\begin{tabular}{|c|c|c|c|c|c|c|c|}
\hline $\begin{array}{c}\text { NOTA/CS: } \\
14-15\end{array}$ & NP & {$[0,3)$} & {$[3,4)$} & {$[4,5)$} & {$[5,7)$} & {$[7,10]$} & TOTAL (\%) \\
\hline NP & 55,56 & 17,65 & 12,50 & 18,18 & 10,00 & 3,03 & 12,35 \\
\hline$[0,3)$ & 22,22 & 52,94 & 56,25 & 0 & 25,00 & 15,15 & 22,22 \\
\hline$[3,4)$ & 7,41 & 11,77 & 6,25 & 27,27 & 15,00 & 13,64 & 13,17 \\
\hline$[4,5)$ & 14,82 & 5,88 & 18,75 & 18,18 & 27,50 & 18,18 & 18,52 \\
\hline$[5,7)$ & 0 & 11,77 & 6,25 & 36,36 & 20,00 & 42,42 & 29,22 \\
\hline$[7,10]$ & 0 & 0 & 0 & 0 & 2,50 & 7,58 & 4,53 \\
\hline TOTAL & $\mathbf{2 7}$ & $\mathbf{1 7}$ & $\mathbf{1 6}$ & $\mathbf{1 1}$ & $\mathbf{4 0}$ & $\mathbf{1 3 2}$ & $\mathbf{2 4 3}$ \\
\hline
\end{tabular}

Las circunstancias que el equipo docente apreció que podían explicar las discrepancias entre las calificaciones derivadas de los cuestionarios y las calificaciones finales encontraron su respaldo en lo que un grupo de estudiantes de ingeniería refirió en unas entrevistas relato. Una era el tiempo escaso transcurrido que mediaba entre expresar las respuestas a un examen tutelado estrechamente y otro no igual pero sí parejo, comparado con el mucho más largo lapso de tiempo que pasaba hasta que se desarrollaban pruebas globales convencionales: son numerosas las realidades que nos exponen que poco queda de una acción educativa al cabo de unos años (Sanmartí y Masip, 2011), y aun tras períodos mucho más cortos. Otras circunstancias eran ejercicios esporádicos de pillería (que quisieron ser sorteados y se había procedido para que así fuera), así como la inexistencia clara de límites a un uso de documentación de sostén (sobre papel o vista en pantalla) o a un empleo de software matemático para los cuestionarios, sea de vuelo pequeño o mayor, mientras que sí que existían, en cambio, límites en el resto de pruebas.

Valorando el contenido de la experiencia del primer año, desde una configuración a la vez cooperativa, reconstructiva y reflexiva, y calculando la oportunidad de su reapert, el equipo docente vio motivos para considerar oportuna una prórroga de la experiencia introduciendo modificaciones tendentes a aumentar el bajo nivel de los cuestionarios como descriptores de calificaciones finales.

(cc) EY-NC-ND 2016, Universitat Politècnica de València 
Se ha incrementado el banco de preguntas diferentes en un 30\%, justo en el tránsito del primer al segundo año, con objeto de enfrentarse a algunas de las causas de diferencias entre los niveles de éxito en los cuestionarios y en las pruebas globales.

Se ha administrado un sexto cuestionario doble, en esta misma translación, consiguiéndose envolver así todas las unidades temáticas de la asignatura. Asimismo se ha equilibrado el número de preguntas de todos los cuestionarios, estando dicho número en el máximo del primer año, promoviéndose una estructura uniforme.

En el segundo año de la experiencia el número de matriculados en la asignatura fue de 220, entre alumnos nuevos y repetidores. La tabla 6 recoge el número total de estudiantes que respondió cada uno de los doce cuestionarios (seis cuestionarios dobles: adaptativo (QA) y simple (QS); han seguido siendo muchos, aunque algunos no respondieran ninguno. Incorpora también la nota media obtenida en cada uno de ellos (sobre 10) (considerando el total de alumnos y considerando sólo los presentados). Apunta, finalmente, el porcentaje de los que han respondido, sea sobre los que han contestado por lo menos en una ocasión, sea sobre el total.

Tabla 6: Gra do de participación y notas obtenidas el segundo año, cuestionario a cuestionario

\begin{tabular}{|c|c|c|c|c|c|c|c|c|c|c|c|c|}
\hline $\begin{array}{l}\text { Total } \\
\text { presentados } \\
15-16\end{array}$ & 160 & 157 & 155 & 151 & 155 & 150 & 152 & 144 & 141 & 131 & 107 & 105 \\
\hline $\begin{array}{l}\text { Nota media } \\
\text { sobre total }\end{array}$ & 4,88 & 5,28 & 4,76 & 5,14 & 5,40 & 5,39 & 4,31 & 4,50 & 3,85 & 3,18 & 3,23 & 3,25 \\
\hline $\begin{array}{l}\text { Nota media } \\
\text { sobre } \\
\text { presentados }\end{array}$ & 6,71 & 7,39 & 6,75 & 7,48 & 7,66 & 7,91 & 6,23 & 6,88 & 6,01 & 5,34 & 6,65 & 6,82 \\
\hline $\begin{array}{l}\text { \% sobre } \\
\text { presentado } \\
\text { alguna vez }\end{array}$ & 83 & 82 & 81 & 79 & 81 & 78 & 79 & 75 & 73 & 68 & 56 & 55 \\
\hline$\%$ sobre total & 73 & 71 & 70 & 69 & 70 & 68 & 69 & 65 & 64 & 60 & 49 & 48 \\
\hline
\end{tabular}

C1 A C1 S C2 AC2 S C3 A C3 S CA 4 C4 S C5 A C5 S C6 A C6 S

La tabla 7 continúa acopiando información del mismo género que la tabla 6 pero para los cuestionarios en conjunto.

Tabla 7: Grado de participación y notas obtenidas en el segundo año de los cuestionarios en conjunto

\begin{tabular}{|l|c|c|}
\hline $\begin{array}{l}\text { Total de presentados } \\
15-16\end{array}$ & 145 & 140 \\
\hline $\begin{array}{l}\text { Nota media sobre } \\
\text { total }\end{array}$ & 4,40 & 4,46 \\
\hline $\begin{array}{l}\text { Nota media } \\
\text { sobre presentados }\end{array}$ & 6,67 & 6,97 \\
\hline $\begin{array}{l}\% \text { sobre presentado } \\
\text { alguna vez }\end{array}$ & 76 & 73 \\
\hline$\%$ sobre total & 66 & 64 \\
\hline & C A & C S \\
\hline
\end{tabular}

(c) EY-NC-ND 2016, Universitat Politècnica de València 
Plan inicial, progresos explícitos y evaluación de una trama de feedforwarding sobre campus virtual en una asignatura de matemáticas

Se ha podido corroborar, a lo largo de la andadura de la experiencia durante el segundo año, que los estudiantes han proporcionado una respuesta afirmativa nuevamente a los cuestionarios dobles (a pesar de que no fuese imprescindible por "obligatoriedad": el peso completo en la calificación era del $5 \%$ únicamente, un $1 \%$ por cuestionario y seleccionándose exclusivamente los cinco cuestionarios con mayores notas.

Los estudiantes han asumido un nivel de participación que se ha instalado por encima del $55 \%$ persistentemente y que se ha emplazado en las inmediaciones del $80 \%$ en la generalidad de los casos. Confrontando con lo que había sobrevenido a lo largo del primer año de la experiencia cabe observar que la franja de participación se ha modificado sólo en una pequeña medida, ensanchándose por el extremo inferior.

Es incuestionable que un grado de abandono se alcanza principalmente a apreciar cuando se salta desde el cuestionario adaptativo (formativo) al convencional (sumativo), por más que el nivel de deserción se comprueba que se ha visto reducido si se confronta con el que había acontecido durante el primer año.

La tabla 8 enfoca evaluar el grado de relación lineal entre los pares de notas de los cuestionarios dobles. No cabe, con una vista de conjunto y comparando con lo ocurrido en el primer año, apuntar que se haya significativamente producido un cambio .

La calificación del cuestionario convencional realizado tras el adaptativo (aquel en el que hay realimentaciones) ha sido superior en absolutamente todos los casos del segundo año (situación más contundente que el primer año): un resultado que era buscado, un resultado que era el esperado y un resultado que ha sido conseguido.

Tabla 8: Coeficientes de correlación el segundo año entre notas de los cuestionarios dobles

\begin{tabular}{|c|c|c|c|c|c|c|}
\hline $\begin{array}{c}\text { Cuestionario } \\
\text { A/S:1516 }\end{array}$ & CA1/CS1 & CA2/CS2 & CA3/CS3 & CA4/CS4 & CA5/CS5 & CA6/CS6 \\
\hline Tema & $\begin{array}{c}\text { Álgebra } \\
\text { Lineal }\end{array}$ & Geometría & $\begin{array}{c}\text { Introducc. } \\
\text { al } \\
\text { Cálculo }\end{array}$ & $\begin{array}{c}\text { Cálculo } \\
\text { Diferencial }\end{array}$ & $\begin{array}{c}\text { Funciones } \\
\text { Varias Var. }\end{array}$ & Optimización \\
\hline Correlación & 0,88 & 0,90 & 0,93 & 0,90 & 0,88 & 0,93 \\
\hline
\end{tabular}

Se aprecia que las calificaciones introducidas por el cuestionario aportador de nota han sido más bien positivas, aunque de perfil mayoritario que no supera el notable bajo. Los resultados antedichos no han tenido, sin embargo, su "consecuencia conveniente" en las calificaciones finales, según cabe observar en la tabla 9.

Un reconocimiento ocular, elemental y expedito, de la primera matriz de la tabla 9, en lo que concierne a los totales en horizontal (correspondientes a los cuestionarios) y a los totales en vertical (correspondientes a las notas finales) muestra disparidad en las distribuciones, pero mucho menos destacada que en el primer año: así ahora la clase modal $[5,7)$ es la misma para las notas medias de cuestionarios que para las finales. Como ocurría en la tabla del primer año el elevado número de celdas con frecuencias muy bajas dificulta la realización directa de un test de chi-quadrada.

(c) ) EY-NC-ND 2016, Universitat Politècnica de València 
Las matrices 2 y 3 de la tabla 9, con porcentajes, proporcionan otras consideraciones, como que aun siendo la misma su clase modal, en el supuesto de las calificaciones de cuestionarios alberga del orden del $36 \%$ de las mismas mientras que para las calificaciones finales la ocupación es del orden del 30\%.

Tabla 9: Distribución el segundo año de notas finales (en vertical) respecto a distribución de notas de cuestionarios (en horizontal)

\begin{tabular}{|c|c|c|c|c|c|c|c|}
\hline $\begin{array}{c}\text { NOTA/CS: } \\
15-16\end{array}$ & NP & {$[0,3)$} & {$[3,4)$} & {$[4,5)$} & {$[5,7)$} & {$[7,10]$} & TOTAL \\
\hline NP & 21 & 4 & 0 & 2 & 1 & 0 & 28 \\
\hline$[0,3)$ & 8 & 11 & 8 & 0 & 13 & 4 & 44 \\
\hline$[3,4)$ & 3 & 9 & 4 & 5 & 21 & 10 & 52 \\
\hline$[4,5)$ & 4 & 3 & 0 & 0 & 19 & 5 & 31 \\
\hline$[5,7)$ & 0 & 5 & 4 & 2 & 33 & 21 & 65 \\
\hline$[7,10]$ & 0 & 0 & 0 & 0 & 0 & 0 & 0 \\
\hline TOTAL & 36 & 32 & 16 & 9 & 87 & 40 & 220 \\
\hline $\begin{array}{c}\text { NOTA/CS: } \\
15-16\end{array}$ & NP & {$[0,3)$} & {$[3,4)$} & {$[4,5)$} & {$[5,7)$} & {$[7,10]$} & TOTAL \\
\hline$N P$ & 70 & 13,33 & 0 & 6,67 & 3,33 & 0 & 28 \\
\hline$[0,3)$ & 14,82 & 20,37 & 14,82 & 0 & 24,07 & 7,41 & 44 \\
\hline$[3,4)$ & 9,38 & 28,13 & 12,50 & 15,63 & 65,63 & 31,25 & 52 \\
\hline$[4,5)$ & 8,89 & 6,67 & 0 & 0 & 42,22 & 11,11 & 31 \\
\hline$[5,7)$ & 0 & 7,04 & 5,63 & 2,82 & 46,48 & 29,58 & 65 \\
\hline$[7,10]$ & 0 & 0 & 0 & 0 & 0 & 0 & 0 \\
\hline TOTAL (\%) & 14,82 & 13,17 & 6,58 & 3,70 & 35,80 & 16,46 & 220 \\
\hline $\begin{array}{c}\text { NOTA/CS: } \\
15-16 \\
\end{array}$ & NP & {$[0,3)$} & {$[3,4)$} & {$[4,5)$} & {$[5,7)$} & {$[7,10]$} & TOTAL \% \\
\hline $\mathrm{NP}$ & 58,33 & 12,50 & 0 & 22,22 & 1,15 & 0 & 12,73 \\
\hline$[0,3)$ & 22,22 & 34,38 & 50 & 0 & 14,94 & 10 & 20,00 \\
\hline$[3,4)$ & 8,33 & 28,13 & 25 & 55,56 & 24,14 & 25 & 23,64 \\
\hline$[4,5)$ & 11,11 & 9,38 & 0 & 0 & 21,84 & 12,5 & 14,09 \\
\hline$[5,7)$ & \begin{tabular}{|l|}
0 \\
\end{tabular} & 15,63 & 25 & 22,22 & 37,93 & 52,5 & 29,55 \\
\hline$[7,10]$ & 0 & 0 & 0 & 0 & 0 & 0 & 0 \\
\hline TOTAL & 36 & 32 & 16 & 9 & 87 & 40 & 220 \\
\hline
\end{tabular}




\section{Conclusiones}

La evaluación aplicada en matemáticas por medio de la metodología descrita ha dinamizado a los estudiantes, consiguiéndose un seguimiento alto sin refutaciones (ni siquiera discusiones) por parte de los mismos, aun solicitándoles unos lapsos de tiempo y un esfuerzo notables (si bien no desmesurados) a la hora de considerar las preguntas de los cuestionarios. Elaborar los exámenes, en lo que atañe a los bancos de preguntas y de realimentaciones y asimismo en cuanto a forjar variantes, ha requerido del profesorado una asignación elevada de tiempo, sobre todo en el primer año, pero éste no ha opuesto reparos ni al despliegue inicial ni a su reiteración, en este último caso con un coste que ha sido menor. Se trata, pues, de un proceso factible.

Tras una primera edición de la experiencia, se decidió mantener ésta por más tiempo, aunque con la incorporación de algunos cambios. Cabe destacar que se ha alcanzado, con la réplica matizada, en el segundo año, una reducción de la discrepancia entre las calificaciones de los cuestionarios y las calificaciones globales, y que se ha conservado que los cuestionarios adaptativos lleven a cuestionarios convencionales posteriores que son respondidos bien, en términos relativos. Se trata, pues, de un proceso útil.

Se plantea, apuntando hacia el futuro, un contexto de nueva ampliación del banco de preguntas, cambio que parece que ha sido efectivo, pasando de las actuales 24-30 por cuestionario a 30-36 por cuestionario. Se está asimismo estudiando la oportunidad de añadir una evaluación diagnóstica o inicial para cada unidad temática, mediante un cuestionario convencional nuevo más breve. Se está también estudiando que todos los cuestionarios tengan carácter sumativo, por más que la evaluación diagnóstica y la vinculada al cuestionario adaptativo tengan un peso claramente inferior al del cuestionario final convencional $(1 \%$, $2 \%, 7 \%$ sería un planteamiento). Se trata, pues, de un proceso mejorable.

La necesidad mantenida y relevante de variar el rendimiento de los estudiantes, los resultados de investigación reflejados en la literatura sobre "feedforwarding" y la percepción de logros conseguidos emplazan a continuar, de momento, con la experiencia y perfeccionarla, como un paso previo a introducir el formato de cuestionarios dobles (o reiterados) como un proceso con consolidación dentro de la asignatura. Se trata, pues, de un proceso perfilado.

\section{Referencias}

BARTOLOMÉ PINA, A. (2012). "Prólogo" en Cano García, E. (ed) Aprobar o aprender. Estrategias de evaluación en la sociedad red. Barcelona: Laboratori de Mitjans Interactius. Universidad de Barcelona

BENITO, A, y CRUZ, A.(2005), Nuevas claves para la docencia universitaria. Madrid: Narcea

CAMPANARIO, J.M. y OTERO, J. (2000). "La comprensión de los libros de texto" en Didáctica de las Ciencias Experimentales, 2000, vol.18 (2), p. 323-338

CASTAÑEDA, L., (2014). "Nuevas vías para enseñar y aprender en entornos enriquecidos por tecnologías" en Silva, J., Salinas, J. Innovando con TIC en la formación inicial docente. Santiago: Enlaces. Centro de Educación y Tecnología del Ministerio de Educación de Chile

(c) EY-NC-ND 2016, Universitat Politècnica de València 
FABREGAT FILLET, J. et al. (2015). "Proyecto, desarrollo y valoración en la UPC de un caso de feedforwarding en campus virtual” en IN-RED 2015 Congreso de Innovación Educativa y Docencia en Red de la Universitat Politècnica de Valencia. Valencia. Disponible en $<$ http://ocs.editorial.upv.es/index.php/INRED/INRED2015/paper/view/> [Consulta: 2 de abril de 2016] GARGALlO LÓPEZ, B. et al. (2015). "Métodos innovadores y enfoques de aprendizaje en estudiantes" en IN-RED 2015 Congreso de Innovación Educativa y Docencia en Red de la Universitat Politècnica de Valencia.. Valencia. Disponible en <http://dx.doi.org/10.4995/INRED2015.2015.1576> [Consulta: 2 de abril de 2016]

INSTITUTO NACIONAL DE TECNOLOGÍAS EDUCATIVAS Y DE FORMACIÓN DEL PROFESORADO Moodle, plataforma de aprendizaje

http://www.ite.educacion.es/formacion/materiales/184/cd/M1 introduccion/pedaggicamente hablando.html

[Consulta: 2 de abril de 2016]

MORIN, E. (2000). Los siete saberes necesarios para la educación del futuro. Barcelona: Seix Barral.

SANMARTÍ, N.; MASIP, M. (2011) “Cómo hacer que la formación impulse cambios en un centro?” en Aula de innovación educativa, 2011, vol. 201, p. 10-14.

SANTOS GUERRA, M.A. (1999). "20 paradojas de la evaluación del alumnado en la universidad española" en Revista electrónica interuniversitaria de formación del profesorado, 1999, 2(1)

UNIVERSITAT POLITÈCNICA DE CATALUNYA - BARCELONA TECH Información del Campus

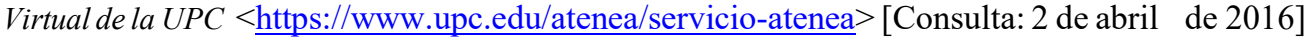

WIRIS Wiris < $\underline{\text { http://www.wiris.com/es/quizzes/docs }>\text { [Consulta: } 2 \text { de abril de 2016] }}$ 